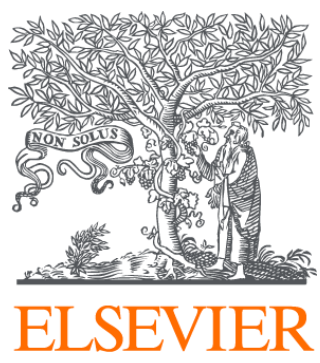

Since January 2020 Elsevier has created a COVID-19 resource centre with free information in English and Mandarin on the novel coronavirus COVID-

19. The COVID-19 resource centre is hosted on Elsevier Connect, the company's public news and information website.

Elsevier hereby grants permission to make all its COVID-19-related research that is available on the COVID-19 resource centre - including this research content - immediately available in PubMed Central and other publicly funded repositories, such as the WHO COVID database with rights for unrestricted research re-use and analyses in any form or by any means with acknowledgement of the original source. These permissions are granted for free by Elsevier for as long as the COVID-19 resource centre remains active. 


\section{Post-Intensive care syndrome and COVID-19: crisis after a crisis?}

One thing that didnot make to the spotlight in this COVID-19 pandemic is a question that what happens to the COVID-19 patients after they are discharged from the critical care? A common assumption around the world is that once a patient is discharged from the hospital and is tested negative the problem is resolved. This may be based on a relative lack of information and knowledge, even among the health care professionals, regarding a condition described as PostIntensive Care Syndrome (PICS). PICS may be a next public health crisis that we may face when this acute form of COVID-19 crisis settles down a bit. It wouldn't be prudent to ignore this serious problem until it becomes another challenge for societies around the world. PICS is characterized by conglomeration of symptoms involving physical strength deficits, cognitive decline, and mental health disturbances observed after discharge from critical care that persist for a protracted amount of time. ${ }^{1}$ Approximately 0.8 million people every year suffer from critical illness requiring mechanical ventilation during their stay in critical care in the United States; beyond all age groups. ${ }^{2}$ Although, data on this topic hasn't been collected yet with COVID-19 patients, it will be reasonable to assume that this number is going to drastically increase because of increase in COVID-19 crises worldwide. At least $20 \%$ of the COVID-19 patients are reported to require supportive care in the critical care units. ${ }^{3}$ Patients infected with COVID-19 who are admitted to critical care often need 10 days of supportive care utilizing mechanical ventilation. ${ }^{4}$ This will result in additional admissions in the intensive care units (ICU) of the hospital for the patients who need supportive care. Approximately $50 \%$ of all the patients, across all ages, admitted to the ICU requiring mechanical ventilation go on developing PICS. ${ }^{5}$ It is interesting to note that the patients who are at risk of developing PICS have history of associated morbidities such as diabetes, hypertension, asthma, chronic obstructive pulmonary disease and prolonged period of mechanical ventilation (because of direct injury to the lungs) that is exactly similar to the clinical profile of COVID-19 patients who are admitted in the ICU of the hospital. ${ }^{3}$

People who survive up to 2 years after discharge form the critical care, may have readmission to nursing care or rehabilitation facility or to ICU again up to the frightening rate of $80 \%{ }^{6}$ This readmission rate is higher in people who have again a similar clinical profile of COVID-19 ICU survivors such as associated morbidities and acute respiratory distress injuries. ${ }^{6}$ Another alarming facet of this problem is long-term cognitive decline. Neurocognitive deficits including anxiety and depression were reported in $46 \%$ of patients at 1 year and $47 \%$ of ICU survivors at 2 year follow up. ${ }^{5}$ Patients also reported consistent deficits in quality of life at 1 and 2 years after discharge with no improvement in emotional, pain and general health over the period of time, rather further deterioration was observed in mental health at 2 years. ${ }^{5}$ Chronic pain after critical care persisting over years may be another reason adding to the mental health disturbances of these patients over the period of time. ${ }^{7}$ Notably, physical impairment such as balance problems and muscular weakness have also been found in these patients over a period of time that can potentially increase the risk of falls in these individuals. Each additional day of bed-rest in the critical care is associated with $11 \%$ decrease in muscle strength even at 24 months of follow up. ${ }^{8}$ Muscle weakness is directly associated with deterioration in health related quality of life and physical function throughout and beyond the 2-years of follow up in ICU survivors of respiratory illness. ${ }^{8}$ Also, there is an alarming impact of PICS on individual's financial stability. A majority of ICU survivors face some problems returning to work with $31 \%$ of them experiencing major occupational changes, and a quarter of them becoming completely jobless. ${ }^{9}$ It doesn't stop here, these patients also develop extreme difficulties in performing their activities of daily living such as driving. It has been reported that $33 \%$ of the individuals after discharge from critical care even up to a year are unable to drive limiting their mobility and social responsibilities. ${ }^{10}$ These are startling statistics and may be an impending disaster in the COVID-19 recovered patients that we are unable to recognize as of now.

Now, another question is what can we do about it? The solution to this problem is developing integrated rehabilitation response by mobilizing our rehabilitation troops and bringing them on the front line to cater these complications of stay in critical care. Professionals such as physical therapists, occupational therapists, psychologists, nutritionist and physical medicine and rehabilitation physicians (physiatrists) can work together to develop strategies to treat the complications arising from ICU stay. Exercise programs tailored towards increasing strength and balance along with good nutrition that may increase the functional capacity should start early after discharge. It has been previously reported that patients recovering from critical care at hospital had improved physical and psychological outcomes when strengthening exercises were supplemented with amino acids. ${ }^{11}$ Many of the patients recovering from ICU may need to be transferred to inpatient rehabilitation settings. However, it poses several challenges such as dire paucity of personal protective equipment which may put rehabilitation professionals at risk. This may result in further spread of disease; health-care provider carrying COVID-19 asymptotically can become a 'super spreader'. ${ }^{12}$

In addition, COVID-19 is a worldwide phenomenon and in many developing countries there are no facilities available for inpatient rehabilitation centers. Ensuring health-care providers and staff safety, and greater out-reach of rehabilitations services, telerehabilitation and virtual rehabilitation may become the mainstay of providing these services. Also, conducting multi-national telerehabilitation conferences may help rehabilitation professionals to develop skills for managing these patients in different parts of the world, and give 
them an opportunity to devise a common framework to address impairments in ICU survivors of COVID-19 patients. Moreover, there is a need of dissemination of awareness of an exigent need of rehabilitation in post-discharge COVID-19 patients in the developing countries where the emphasize on rehabilitation is minimal. Postdischarge crises may hit developing countries harder than developed countries because of lack of basic health social services such as health, education and safety available let alone rehabilitation facilities. ${ }^{13}$ PICS and its implications in COVID-19 ICU survivors should be added in the policy making of the organizations such as world bank or the United Nations when allocating health-care relief funds to the developing countries. Emphasize on rehabilitation should be integrated as an essential part of the support programs such as "Securing Human Investments to Foster Transformation (SHIFT)" aimed at capacity building of developing countries such as Pakistan to fight this pandemic. Lastly, one critical aspect in management of these patients is education to the family members. PICS can have a significant influence on the family members of the patient, and it is called PICS-family. ${ }^{14}$ Patient will be completely dependent on the family after getting discharged from the hospital, and family may important role in emotional and physical support. Family should recognize the mental health disturbances in patients that may have developed because of anxiety and depression, provide continual emotional support and help patient understand the need of physical rehabilitation by engaging them in regular physical activity. This article is an effort to bring this looming yet unrecognized problem to public attention.

PICS is relatively newer term that was introduced almost 10 years ago to health-care professionals involved in the treatment of patients discharged after critical care to identify the impairments that are usually missed by clinicians, and administer tailored care to address these impairments. Hospitalizations because of COVID-19 may demand recognition of PICS more than ever, and sooner than later.

\section{Financial disclosure}

I affirm that I have no financial affiliation (including research funding) or involvement with any commercial organization that has a direct financial interest in any matter included in this manuscript. There were no sources of grant support for this study.

\section{Declaration of Competing Interest}

I report no conflict of interest.

$$
\begin{array}{r}
\text { Abbis Jaffri* } \\
\text { Ume Abbiyha Jaffri } \\
\text { School of Pharmacy and Health Professions, Creighton University, }
\end{array}
$$
Omaha, NE, United States
Bachelors of Medicine, and Bachelors of Surgery, Ameer ud Din Medical College Lahore, Pakistan

*Corresponding author at: School of Pharmacy and Health Professions, Creighton University, 2500 California Plaza Omaha, NE 68178.

E-mail address: abbis.haider@gmail.com (A. Jaffri).

Received 11 June 2020

Accepted 15 June 2020

Available online 18 June 2020

\section{References}

1. Elliott D, Davidson JE, Harvey MA, et al. Exploring the scope of post-intensive care syndrome therapy and care: engagement of non-critical care providers and survivors in a second stakeholders meeting. Crit Care Med. 2014;42(12):2518-2526.

2. Wunsch H, Linde-Zwirble WT, Angus DC, Hartman ME, Milbrandt EB, Kahn JM. The epidemiology of mechanical ventilation use in the United States. Crit Care Med. 2010;38(10):1947-1953.

3. Rodriguez-Morales AJ, Cardona-Ospina JA, Gutiérrez-Ocampo E, et al. Clinical, laboratory and imaging features of COVID-19: a systematic review and meta-analysis. Travel Med Infect Dis. 2020101623.

4. Grasselli G, Zangrillo A, Zanella A, et al. Baseline characteristics and outcomes of 1591 patients infected with SARS-CoV-2 admitted to ICUs of the Lombardy region. Italy. Jama. 2020;323(16):1574-1581.

5. Hopkins RO, Weaver LK, Collingridge D, Parkinson RB, Chan KJ, Orme Jr JF. Twoyear cognitive, emotional, and quality-of-life outcomes in acute respiratory distress syndrome. Am J Respir Crit Care Med. 2005;171(4):340-347.

6. Ruhl AP, Lord RK, Panek JA, et al. Health care resource use and costs of two-year survivors of acute lung injury. An observational cohort study. Ann Am Thorac Soc. 2015;12(3):392-401.

7. Koster-Brouwer ME, Rijsdijk M, van Os WK, et al. Occurrence and risk factors of chronic pain after critical illness. Read Online: Crit Care Med| Soc Crit Care Med. 2020;48(5):680-687.

8. Fan E, Dowdy DW, Colantuoni E, et al. Physical complications in acute lung injury survivors: a 2-year longitudinal prospective study. Crit Care Med. 2014;42(4):849.

9. Kamdar BB, Suri R, Suchyta MR, et al. Return to work after critical illness: a systematic review and meta-analysis. Thorax. 2020;75(1):17-27.

10. Ohtake PJ, Lee AC, Scott JC, et al. Physical impairments associated with post-intensive care syndrome: systematic review based on the world health organization's international classification of functioning, disability and health framework. Phys Ther. 2018;98(8):631-645.

11. Jones C, Eddleston J, McCairn A, et al. Improving rehabilitation after critical illness through outpatient physiotherapy classes and essential amino acid supplement: a randomized controlled trial. J Crit care. 2015;30(5):901-907.

12. Beeching NJ, Fletcher TE, Beadsworth MB. Covid-19: testing times. Br Med J Publ Group. 2020.

13. Loayza NV, Pennings S. Macroeconomic policy in the time of COVID-19: a primer for developing countries. World Bank. 2020.

14. Needham DM, Davidson J, Cohen H, et al. Improving long-term outcomes after discharge from intensive care unit: report from a stakeholders' conference. Crit Care Med. 2012;40(2):502-509. 